\title{
TU/e emonownen

\section{On-demand wrinkling patterns in thin metal films generated from self-assembling liquid crystals}

\section{Citation for published version (APA):}

Haan, de, L. T., Leclère, P. E. L. G., Damman, P., Schenning, A. P. H. J., \& Debije, M. G. (2015). On-demand wrinkling patterns in thin metal films generated from self-assembling liquid crystals. Advanced Functional Materials, 25(9), 1360-1365. https://doi.org/10.1002/adfm.201403399

DOI:

10.1002/adfm.201403399

Document status and date:

Published: 01/01/2015

\section{Document Version:}

Publisher's PDF, also known as Version of Record (includes final page, issue and volume numbers)

\section{Please check the document version of this publication:}

- A submitted manuscript is the version of the article upon submission and before peer-review. There can be important differences between the submitted version and the official published version of record. People interested in the research are advised to contact the author for the final version of the publication, or visit the $\mathrm{DOI}$ to the publisher's website.

- The final author version and the galley proof are versions of the publication after peer review.

- The final published version features the final layout of the paper including the volume, issue and page numbers.

Link to publication

\section{General rights}

Copyright and moral rights for the publications made accessible in the public portal are retained by the authors and/or other copyright owners and it is a condition of accessing publications that users recognise and abide by the legal requirements associated with these rights.

- Users may download and print one copy of any publication from the public portal for the purpose of private study or research.

- You may not further distribute the material or use it for any profit-making activity or commercial gain

- You may freely distribute the URL identifying the publication in the public portal.

If the publication is distributed under the terms of Article 25fa of the Dutch Copyright Act, indicated by the "Taverne" license above, please follow below link for the End User Agreement:

www.tue.nl/taverne

Take down policy

If you believe that this document breaches copyright please contact us at:

openaccess@tue.nl

providing details and we will investigate your claim. 


\title{
On-Demand Wrinkling Patterns in Thin Metal Films Generated from Self-Assembling Liquid Crystals
}

\author{
Laurens T. de Haan, Philippe Leclère, Pascal Damman, Albertus P. H. J. Schenning, \\ and Michael G. Debije**
}

In this work, a new, universal method is described that uses the photopatterning of liquid crystals, which is accurately translated into a controlled, intricately wrinkled metal surface. Remarkably, the patterns have an oscillation in amplitude of the wrinkles. This rapid method allows generation of intricate multidomain patterns and continuous circular structures, including azimuthal, radial, and even higher complexity arrangements as examples. These wrinkled gold surfaces are also strikingly visual, which is interesting for applications ranging from diffractive elements to fine jewelry.

\section{Introduction}

Over the past decade surface wrinkling has been a topic of intense research from the scientific community. ${ }^{[1]}$ Controlled, programmed wrinkle formation would provide a quick and easy method for the spontaneous generation of a variety of microstructured surfaces over large areas. In this work, we describe a new, universal method using the photopatterning of anisotropic liquid crystal (LC) polymer networks which are accurately translated into a controlled, intricately wrinkled gold surface. Photoalignment of polymerizable LCs is followed by photopolymerization and sputter coating of a gold layer, which induces compressive stress in the system. ${ }^{[2]}$ Heating the material above the glass transition temperature releases stresses through wrinkling; these wrinkles form perpendicular to the alignment director of the LC network due to the lower elastic modulus in that direction (see Figure 1a). ${ }^{[3]}$ We control the alignment director of the LC network using photoalignment

Dr. L. T. de Haan, Prof. A. P. H. J. Schenning, Dr. M. G. Debije

Functional Organic Materials and Devices Department of Chemical Engineering and Chemistry Eindhoven University of Technology

Den Dolech 2, 5600, MB, Eindhoven, Netherlands

E-mail:m.g.debije@tue.nl

Dr. P. Leclère

Laboratory for Chemistry of Novel Materials

University of Mons

Place du Parc 20, B 7000, Mons, Belgium

Prof. P. Damman

Laboratoire Interfaces and Fluides Complexes

University of Mons

Place du Parc 20, B-7000, Mons, Belgium

DOI: 10.1002/adfm.201403399 layers in combination with simple photomasks in a contactless process, ${ }^{[4,5]}$ spontaneously generating unique wrinkling patterns in any arbitrarily complex fashion.

Wrinkling can be induced in bilayer systems consisting of a thin film of a relatively stiff material on top of a foundation of a softer material as a result of a strain mismatch between the layers, usually induced by mechanical or heat-driven deformation of the foundation or the top layer. It is a well-studied and well-understood process. ${ }^{[6-9]}$ Many applications for wrinkled surfaces have been demonstrated, including preparation of superhydrophobic ${ }^{[10]}$ and antifouling surfaces, ${ }^{[11]}$ actuators, ${ }^{[12]}$ alignment of living cells, ${ }^{[13]}$ optical focusing, ${ }^{[14]}$ fabrication of microlens arrays, ${ }^{[15]}$ fabrication of patterned electrodes, ${ }^{[16]}$ stretchable conductors, ${ }^{[17]}$ and strain-sensitive diffraction gratings. ${ }^{[18]}$ Achieving precise control over the wrinkling properties is vital for the further development of these applications. The amplitude and period of the wrinkles can be easily tuned by changing the thickness of the thin, stiff top layer, ${ }^{[19,20]}$ and the preparation of homogeneously wrinkled surfaces is rather straightforward. ${ }^{[1,9,20,21]}$ A limited number of patterns over small surface areas have been reported..$^{[6,22-26]}$ However, it is desirable to introduce a flexible method of generating complex wrinkle patterns on demand, scalable to cover large areas. We demonstrate the power of our method by generating intricate multidomain patterns and continuous circular structures including azimuthal, radial, and even higher complexity arrangements as examples, without the need of multiple master patterns and the possibility of rapidly switching between patterns with simple rearrangement of light source, polarizers, and masks.

\section{Results and Discussion}

We make our wrinkling patterns using photoalignment of polymerizable LCs. ${ }^{[27,28]}$ Alignment cells were prepared by combining two glass plates coated with a linearly photopolymerizable polymer which was photoaligned by exposure to polarized ultraviolet light through a variety of photomasks (Figure $1 \mathrm{~b}, \mathrm{c}) \cdot{ }^{\left[{ }^{[4]}\right.}$ The cells were filled with a mixture of polymerizable LCs (Figure 1d) at $80^{\circ} \mathrm{C}$ in the isotropic phase, and were photopolymerized at $60^{\circ} \mathrm{C}$ in the nematic phase into a polymer film having a glass transition temperature of around $45^{\circ} \mathrm{C} \cdot{ }^{[4]}$ The cell was opened by removing one of the glass plates, and a gold 
a

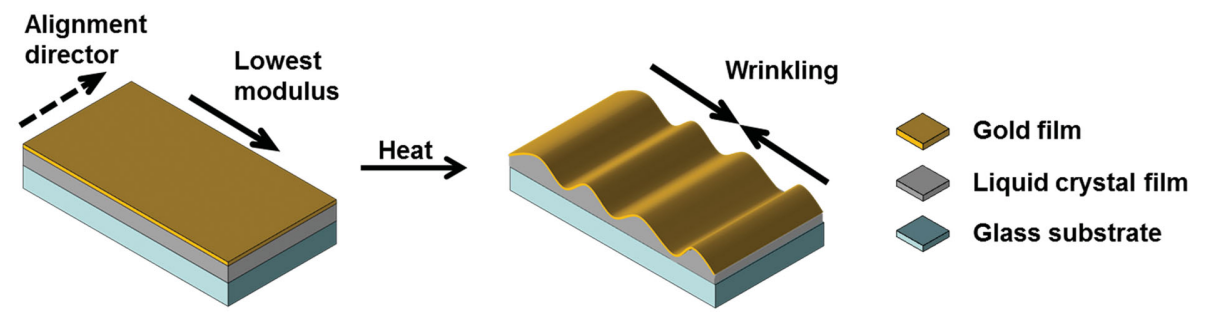

b

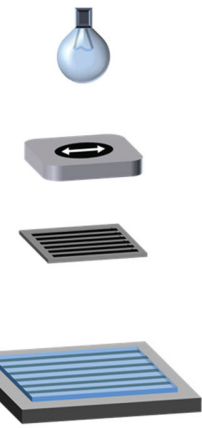

C

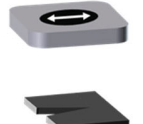

d
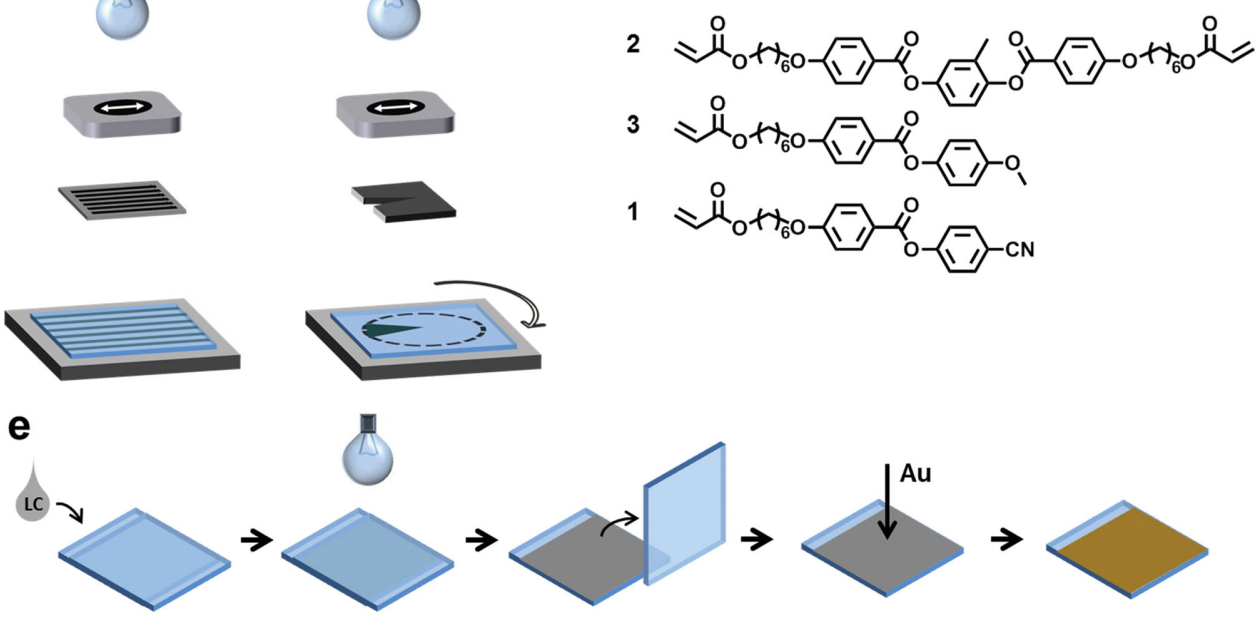

Figure 1. a) Mechanism of wrinkle formation. Heating causes the liquid crystal network to go through the glass transition, which allows release of the stress in the gold layer through wrinkling, which takes place in the direction with the lowest modulus. b) Photoalignment setup used for the preparation of discrete patterns. c) Photoalignment setup used for the preparation of continuous circular patterns. It consists of a UV lamp, a polarizer, a photomask, and the substrate bearing the photoalignment layer. d) Polymerizable liquid crystals and the ratio (by mass) in which they were used. e) Preparation procedure to make the wrinkle patterns out of the patterned alignment cells.

layer was sputter coated on top of the solid LC film (Figure 1e). Putting the material on a hotplate at $60{ }^{\circ} \mathrm{C}$ then caused wrinkles to appear in a few minutes, which could be readily detected as a transition from a reflective to a diffractive surface (see the video in the Supporting Information). Upon cooling to room temperature, the patterns remain, revealing that the wrinkling is an irreversible process. The presence of the wrinkles was confirmed through optical microscopy (Figure 2a), and it was clear that the wrinkles always extend parallel to the alignment director of the underlying LC network. This is in contrast to previous research using a crosslinked LC network as the foundation, where the wrinkles always ran perpendicular to the alignment director when formed upon heating, ${ }^{[29-31]}$ or parallel to the director when formed upon cooling. ${ }^{[29,30,32]}$ In the latter cases, the anisotropic contraction of the LC network, which takes place parallel to the director upon heating, was responsible for the formation of wrinkles. Additional films were made using sputter-coated copper layers, and these produced wrinkling patterns which also followed the order of the underlying LC polymer pattern (see Supporting Information Figure S1). Films without a metal layer were also heated and measured by profilometry and observed by optical microscopy and were determined to be essentially featureless: no regular wrinkling pattern could be identified.

To test if anisotropic deformation in the LC network was required for wrinkle formation in our samples, an isotropic LC network was prepared by polymerization at a temperature above the nematic-to-isotropic transition. When a gold layer was applied to this network, wrinkling still took place after heating, but the wrinkles were randomly oriented (Figure 2b). These random wrinkles were similar to the aligned wrinkles (see also Figure 3e), which indicates that their formation is strictly caused by the changing materials properties during heating, and the anisotropy only serves to steer the wrinkling in a specific direction. We therefore assume that compressive stress induced in the gold layer during the sputter coating process ${ }^{[2]}$ is the driving force for wrinkling. This uniform compressive stress was also deduced from the labyrinthine morphology of wrinkles observed for similar metal polymer systems. ${ }^{[27,28]}$ At room temperature, this stress $(\delta)$ is below the critical stress $\left(\delta_{\mathrm{c}}\right)$ required to induce wrinkling of the gold film according to $\delta>\delta_{\mathrm{c}}$ $=\left(E_{\mathrm{p}} / E_{\mathrm{m}}\right)^{2 / 3}$, where $E_{\mathrm{p}}$ and $E_{\mathrm{m}}$ are the elastic moduli of the polymer layer and the metal films, respectively (see Scaling Model in the Supporting Information for more details). This creates a metastable state in which wrinkling does not yet take place. Upon heating the LC network foundation (likely above the glass transition temperature), the modulus $E_{\mathrm{p}}$ abruptly decreases, lowering the critical stress below the compressive stress and allowing wrinkling to occur. The modulus of the LC network is anisotropic, with the lowest modulus perpendicular to the alignment director, dictating that the film will buckle perpendicular to the alignment director, and as a result the wrinkles will always extend parallel to the alignment director (Figure 1a). 
a

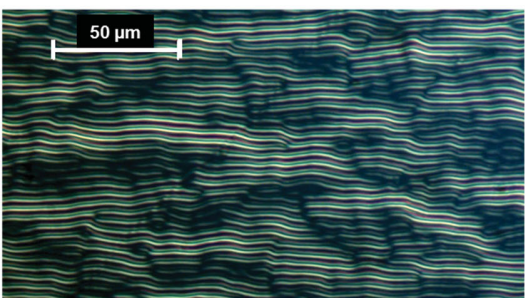

C

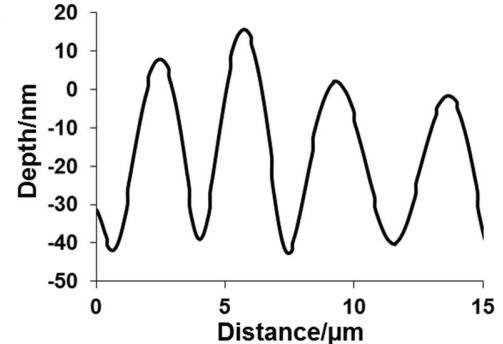

e

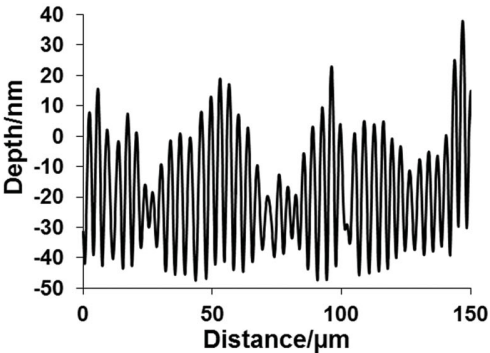

b

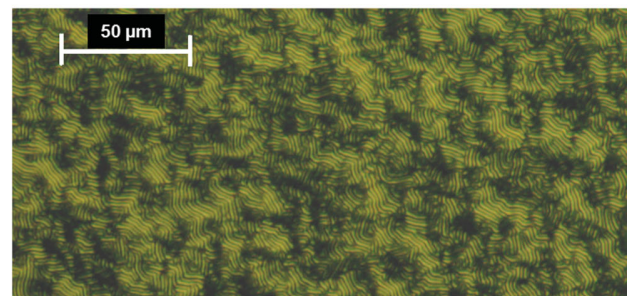

d

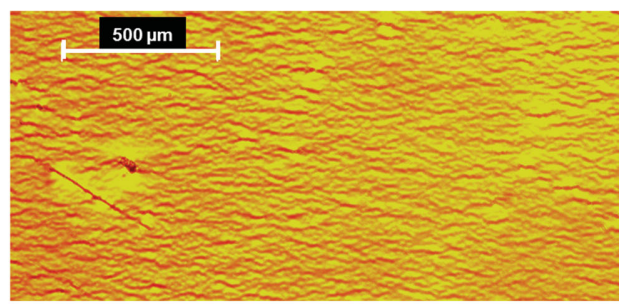

f

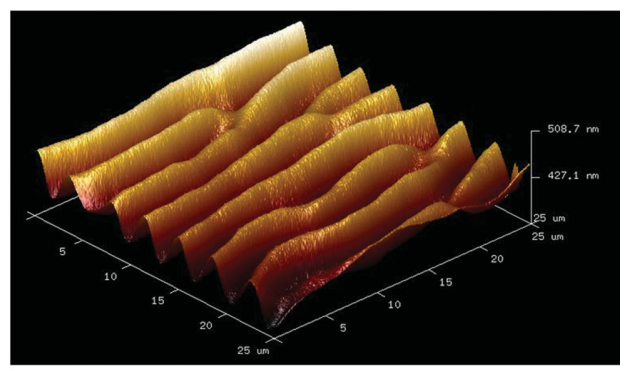

Figure 2. a) Optical microscopy image of a wrinkled surface. b) Optical microscopy picture of a wrinkled surface on an isotropic liquid crystal foundation, showing randomly oriented wrinkles. c) Typical surface profile of the wrinkled gold surface. d) Zoom-out microscopy picture of the second-order, larger wrinkles in which the smaller wrinkles are nested. e) The same surface profile, viewed over a longer distance to show the second-order wrinkles. f) AFM image of the wrinkled surface.

An alternative explanation for the wrinkling observed could be the compressive stress in the LC layer. ${ }^{[33]}$ In previous reports, heating aligned LC films decreased the molecular order, causing shrinkage along the director, resulting in noncompression and a wrinkling pattern perpendicular to the molecular director. ${ }^{[29,30]}$ This explanation does not obviously account for our observed wrinkling extending parallel to the director; moreover, our wrinkling patterns only appear upon heating to a specified temperature. Once grown, these parallel wrinkles rigidify the structure and prevent the formation of wrinkles along another direction, an effect that is reminiscent of the high rigidity observed for corrugated cardboards.

The wrinkled surfaces were further studied using surface profilometry: a typical profile, viewed over a $15 \mu \mathrm{m}$ distance, is shown in Figure 2c. Surprisingly, when viewed over longer distances it became clear that the profiles show a strong periodic variation in peak height, forming what seems to be a secondorder hierarchically wrinkled structure (Figure 2d,e). Hierarchical wrinkling has been previously reported in the literature, taking place when the amplitude of the wrinkles reaches a maximum, causing the wrinkled layer to act as a much thicker "effective layer" which then wrinkles with a much longer period. ${ }^{[34]}$ However, in our case the smaller wave has varying amplitude, which is not expected for hierarchical wrinkling. AFM was used to confirm the profilometry measurements, and showed a wrinkled surface with similar characteristics (Figure 2f). We observed that the wrinkle amplitude and period increased with thicker gold layers, which is expected due to the relations $\lambda=h\left(E_{\mathrm{m}} / E_{\mathrm{p}}\right)^{1 / 3}$, where $h$ is the thickness of the metal film, and $\delta=A^{2} / \lambda^{2}$, where $A$ is the wrinkle amplitude. We also observed that when thicker gold layers were used, the surface became more irregular (see Supporting Information Figure S2).

From a purely physical point of view, wrinkles and modulation should be characterized by different lengthscales. To build these lengthscales, we make use of the relevant parameters involved in the mechanics of the bilayer: elastic moduli, $E_{\mathrm{m}}$, $E_{\mathrm{p}}$, the metal thickness, $h$, and the polymer film thickness, $H$ (the surface free energies should not be considered since no change in area is observed due to inextensibility). For such metal-polymer bilayers, there are two different asymptotic regimes to account for the wrinkling process. If the polymer thickness is much larger than the wavelength, the soft foundation can be assumed to be infinite. In this regime, the wrinkle period is determined by the relation, $\lambda_{\mathrm{h}}=6.3 h\left(E_{\mathrm{m}} / E_{\mathrm{p}}\right)^{1 / 3}$ (see the Supporting Information). In the other asymptotic regime, the film thickness is smaller than the wavelength and the period is now given by the relation, $\lambda_{\mathrm{hH}}=5.4(h H)^{1 / 2}\left(E_{\mathrm{m}} /\right.$ $\left.E_{\mathrm{p}}\right)^{1 / 6} \cdot{ }^{[25]}$ In the bilayers studied here, we are in between these two regimes. Thus, for the initial stages of buckling, that is, for small amplitude of wrinkles, the wrinkling wavelength should be given by the relation $\lambda_{\mathrm{h}}$ which yields a value close to $4 \mu \mathrm{m}$. When the wrinkle amplitude increases, we expect a symmetry breaking. In other words, the infinite soft foundation assumption no longer holds and the wavelength should be determined 
www.MaterialsViews.com

a

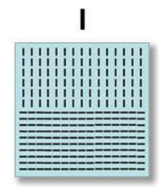

II

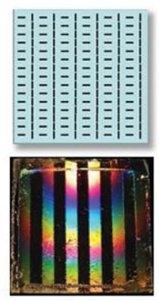

III

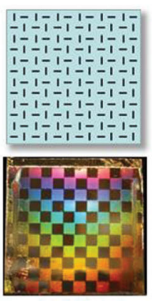

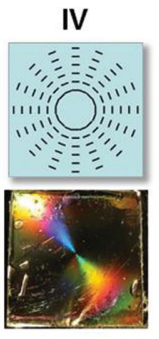
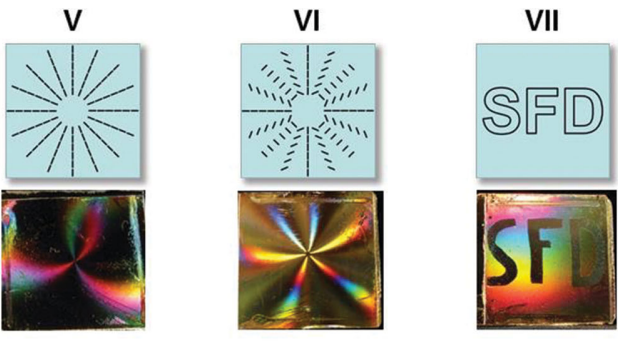

b

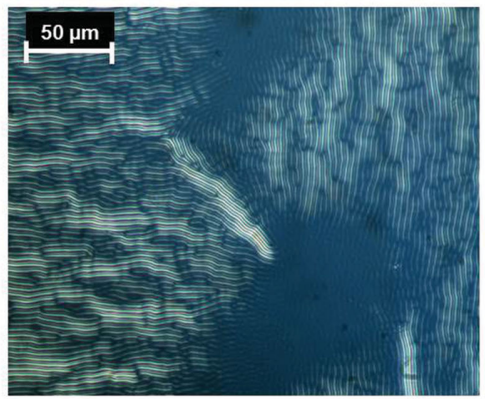

c

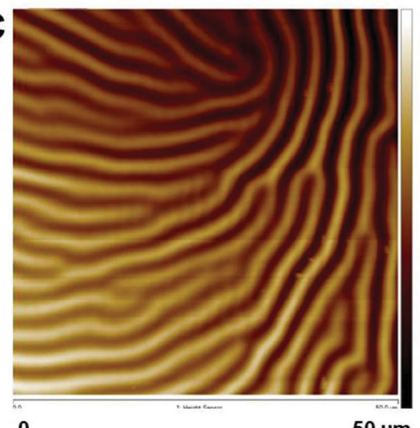

e

\begin{tabular}{|c|c|c|c|c|}
\hline Pattern & \multicolumn{2}{|c|}{$\begin{array}{l}\text { Average } \\
\text { period } \\
(\mu \mathrm{m})\end{array}$} & \multicolumn{2}{|c|}{$\begin{array}{l}\text { Average } \\
\text { height } \\
(\mathrm{nm})\end{array}$} \\
\hline \multirow[t]{2}{*}{ I } & II & $\perp$ & II & $\perp$ \\
\hline & $\begin{array}{l}3.5 \\
3.5 \\
3.4 \\
3.6\end{array}$ & $\begin{array}{l}3.7 \\
3.6 \\
3.6 \\
3.7\end{array}$ & $\begin{array}{l}38 \\
36 \\
38 \\
40\end{array}$ & $\begin{array}{l}46 \\
42 \\
39 \\
49\end{array}$ \\
\hline II & $\begin{array}{l}3.2 \\
3.2 \\
3.3\end{array}$ & $\begin{array}{l}3.6 \\
3.8 \\
3.2\end{array}$ & $\begin{array}{l}47 \\
48 \\
52\end{array}$ & $\begin{array}{l}70 \\
75 \\
48\end{array}$ \\
\hline III & \multicolumn{2}{|c|}{$\begin{array}{l}2.5 \\
2.4 \\
2.5\end{array}$} & \multicolumn{2}{|c|}{$\begin{array}{l}22 \\
21 \\
23\end{array}$} \\
\hline IV & \multicolumn{2}{|c|}{3.1} & \multicolumn{2}{|c|}{45} \\
\hline V & \multicolumn{2}{|c|}{3.9} & \multicolumn{2}{|c|}{54} \\
\hline VI & \multicolumn{2}{|c|}{3.5} & \multicolumn{2}{|c|}{61} \\
\hline isotropic & \multicolumn{2}{|c|}{ N/A } & \multicolumn{2}{|c|}{$\begin{array}{l}35 \\
34 \\
36\end{array}$} \\
\hline
\end{tabular}

d

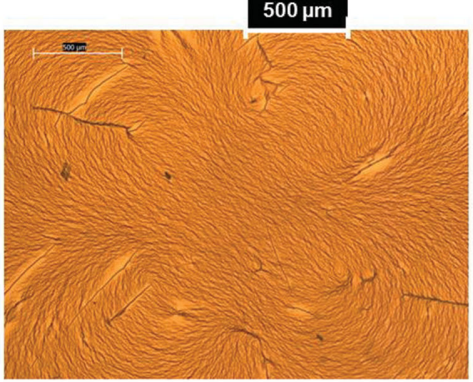

f

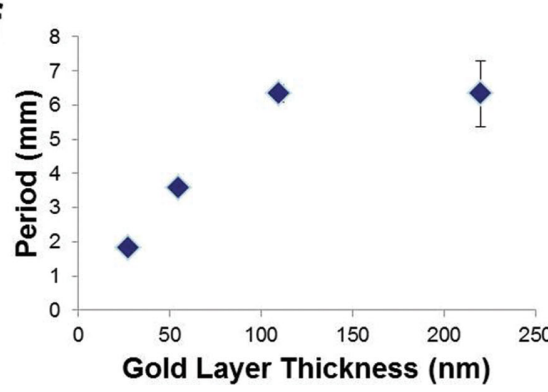

Figure 3. a) Overview of the different patterns, both schematically and visually. In pattern VII, the wrinkles extend vertically within the text (parallel to the straight edge of the $D$ ) and horizontally around it. b) Microscopy image of the domain border in pattern I. c) AFM image of the domain border in pattern II. d) Microscopy image of the center of pattern VI. The four "lobes" in the pattern are clearly visible. e) Table showing the average wrinkle period and height of patterns I-VI, as measured with profilometry on a $400 \mu \mathrm{m}$ trajectory at multiple locations. For patterns with rectangular domains (I and II), the data are divided between measurements parallel and perpendicular to the long axis of the domain. The amplitude of the wrinkles on the isotropic network is also shown, although the period could not be accurately measured. f) Plot of the measured average wrinkle period as a function of sputtered gold layer thickness as estimated from standard sputter coater deposition rate. The pattern was measured over a 400 um length and the average distance between each peak and valley was calculated. For each sample, 3-4 measurements were carried out.

by the alternate relation, $\lambda_{\mathrm{hH}}$, which gives a much larger period around $30 \mu \mathrm{m}$. The final configuration should correspond to a superposition of these two wavelengths, similar to the observed morphology. These two limits correspond to the observed values for both wrinkles and modulation (see Figure 2).

Cells with various alignment patterns (Figure 3a) were used to prepare a variety of unprecedented alignment profiles within the LC networks. Discrete patterns, such as lines (patterns I and II), squares (pattern III), and text (pattern VII), were prepared using photomasks (Figure 1b). Continuous circular patterns, such as azimuthal (pattern IV), radial (pattern V), and an even higher complexity pattern with defect strength $+3^{[5]}$ (pattern VI), were prepared through photoalignment on a rotating substrate (Figure 1c). ${ }^{[4]}$ The samples diffract light perpendicular to the alignment direction of the wrinkles, which allows visual characterization of the patterns and results in striking optical effects. We also analyzed the patterns more closely with microscopy, noticing the relatively smooth and localized boundary transition between two domains (Figure 3b,c). Of special interest is pattern VI (Figure 3d), which would be especially difficult to prepare using LC alignment by traditional rubbing techniques, for example, and show that complex patterns can be fabricated on demand.

To determine if the domain sizes of the different patterns had any effect on the period and/or amplitude of the wrinkles, we performed an in-depth analysis of patterns I, II, and III generated in the $20 \mathrm{~nm}$ gold layer, and the average wrinkle height and period were determined for all three alignments (Figure 3e). For the two samples with rectangular domains (pattern I and II), the results were grouped based on whether the wrinkle direction in the measured domain was parallel or perpendicular to the long axis of the domain. It appears that wrinkles in the domains perpendicular to the long axis are quite similar in period and height compared to domains parallel to the long axis. A series of samples were measured for patterns displaying $1,2,4,12$, and 36 domains per side (with $1,4,16,144$, and 1296 individual "squares") produced on LC layers of between 7 and $30 \mu \mathrm{m}$ thick: the variations were not 
large and there was no obvious correlation between LC layer patterning and the period and amplitude of the generated wrinkles (see Figure $3 \mathrm{f}$ and Supporting Information Figure S3). As evidenced by Figure $3 \mathrm{f}$, there is a general linear relation between the period of the wrinkling and the gold layer thickness until thick (>125 nm) gold layers have been deposited. The surface textures of the samples alter dramatically with increased thickness: at the thickest layers, the surfaces appear littered with additional cracks or other deformities (See Supporting Information Figure S1). At least at the distance scales of these experiments, there is little impact of the proximity of the domain boundaries on either the height or period of the wrinkling. This allows reproducible wrinkling over a range of pattern sizes and forms.

Using the same technique, we also examined the films with curved patterns (Figure 3a, patterns IV-VI). From these pictures, it becomes clear that the wrinkles also follow the curved alignment of the LC network. We performed profilometry measurements on pattern VI (Figure 3e) at locations far from the central region, as the strong curvature of the wrinkles near the center distorted the results. The wrinkle amplitude and depth were comparable to patterns I and II. This implies that continuous circular patterns behave similarly to discrete patterns. Thus, the photopatterning technique allows generation of a myriad of different wrinkling alignments without adversely affecting the periodicity or height of the wrinkling pattern.

\section{Conclusion}

In conclusion, we have demonstrated a simple, contactless method to generate well-defined, controlled, and complex wrinkling patterns by sputter coating a thin layer of gold on photoaligned LC networks, followed by heating. The wrinkling always takes place perpendicular to the alignment director of the LC network, due to the lower modulus in that direction. Interestingly, we observed a remarkable periodic oscillation in the amplitude of the wrinkles. There appears to be little or no dependence of wrinkle period and height on the specific pattern, suggesting that the proximity of pattern boundaries has little impact on the wrinkle formation. The method is versatile, straightforward, and does not require a complex setup or expensive masters or masks. In addition, photoalignment has found its way into commercial production, suggesting our more complex photopatterned systems could be applied over large surfaces, if desired. ${ }^{[35,36]}$ We show that complex diffraction gratings can be prepared using this technique, with applications ranging from alignment of cells and patterned electronics to fine jewelry.

\section{Experimental Section}

A photoalignment material (ROP-108, Rolic) was spin coated on clean $30 \mathrm{~mm} \times 30 \mathrm{~mm}$ glass substrates at 1500 RPM for $30 \mathrm{~s}$, followed by brief heating to $115^{\circ} \mathrm{C}$ to remove the solvent. The substrates were glued into cells using $18 \mu \mathrm{m}$ spacers (the effect of LC layer thickness was minimal: see Figure S4, Supporting Information). The completed cells were then subjected to irradiation with polarized UV light via mask exposure in various ways to create the patterns (Figure $1 \mathrm{~b}, \mathrm{c}$ ). The cells were filled at $80^{\circ} \mathrm{C}$ with a mixture of reactive LCs (RM82, RM105, and RM23 in a 2:3:1 ratio, Merck) containing a radical initiator (Irgacure 819, Ciba) to allow photopolymerization, and an inhibitor (t-bhq, Fluka) to prevent thermal polymerization. The filled cell was allowed to cool to $60^{\circ} \mathrm{C}$, after which the mixture was cured for 5 min using UV irradiation. After cooling to room temperature, one plate of the cell was removed. The alignment of the films was confirmed by observation under crossed polarizers; $;{ }^{[4]}$ a representative image of an azimuthal sample viewed under crossed polarizers may be found in the Supporting Information as Figure S5). The polymer film was sputter coated with gold at room temperature (the actual temperature of the film during gold sputtering is not known) in an Emitek $\mathrm{K} 575 \mathrm{X}$ sputter coater operated at $65 \mathrm{~W}$, where the sputtering duration determined the thickness of the gold layer. The gold-coated LC films were heated on a hot stage at $60{ }^{\circ} \mathrm{C}$ (the glass transition temperature of the $\mathrm{LC}$ polymer was about $45^{\circ} \mathrm{C}$ ) until wrinkling became visible due to the optical effects caused by the generation of diffractive structures (see the video in the Supporting Information). The correlation between LC film alignment and gold wrinkling directions were confirmed by carefully marking the samples before sputtering. The entire procedure for producing the films is depicted in Figure 1. The surface of one of the films was observed through an optical microscope (Leica DM-6000M)), and a profilometer (Veeco Dektak 150, Bruker) was used to characterize the surface of all the samples.

\section{Supporting Information}

Supporting Information is available from the Wiley Online Library or from the author.

\section{Acknowledgements}

The authors wish to thank Jelle Stumpel for his assistance in producing the optical microscopy image, and Samantha J. Basalo Vázquez, Jeroen Dobbelaar, Ary J. Janse, Roeland F. Kooiman, Jelle Penders, and Michelle Raven for their help in measuring the effect of thickness of the liquid crystal layer on the wrinkling.

Received: September 29, 2014 Revised: October 29, 2014 Published online: December 28, 2014

[1] C. M. Chen, S. Yang, Polym. Int. 2012, 61, 1041.

[2] J. A. Thornton, D. W. Hoffman, Thin Solid Films 1989, 171, 5

[3] H. Vandeparre, S. Desbief, R. Lazzaroni, C. Gay, P. Damman, Soft Matter 2011, 7, 6878.

[4] L. T. de Haan, C. Sánchez-Somolinos, C. W. M. Bastiaansen, A. P. H. J. Schenning, D. J. Broer, Angew. Chem. Int. Ed. 2012, 51, 12469.

[5] M. E. McConney, A. Martinez, V. P. Tondiglia, K. M. Lee, D. Langley, I. I. Smalyukh, T. J. White, Adv. Mater. 2013, 25, 5880.

[6] N. Bowden, S. Brittain, A. G. Evans, J. W. Hutchinson, G. M. Whitesides, Nature 1998, 393, 146.

[7] F. Brau, H. Vandeparre, A. Sabbah, C. Poulard, A. Boudaoud, P. Damman, Nat. Phys. 2011, 7, 56.

[8] E. Cerda, L. Mahadevan, Phys. Rev. Lett. 2003, 90, 074302.

[9] L. Pocivavsek, R. Dellsy, A. Kern, S. Johnson, B. Lin, K. Y. C. Lee, E. Cerda, Science 2008, 320, 912.

[10] Y. Li, S. Dai, J. John, K. R. Carter, ACS Appl. Mater. Interfaces 2013, 5, 11066.

[11] K. Efimenko, J. Finlay, M. E. Callow, J. A. Callow, J. Genzer, ACS Appl. Mater. Interfaces 2009, 1, 1031.

[12] M. Watanabe, H. Shirai, T. Hirai, J. Appl. Phys. 2002, 92, 4631.

[13] P. Yang, R. M. Baker, J. H. Henderson, P. T. Mather, Soft Matter 2013, 9, 4705. 
[14] R. Li, H. Yi, X. Hu, L. Chen, G. Shi, W. Wang, T. Yang, Sci. Rep. 2013, 3, 2775.

[15] E. P. Chan, A. J. Crosby, Adv. Mater. 2006, 18, 3238.

[16] H. Wu, M. Menon, E. Gates, A. Balasubramanian, C. J. Bettinger, Adv. Mater. 2014, 26, 706.

[17] S. P. Lacour, S. Wagner, Z. Huang, Z. Suo, Appl. Phys. Lett. 2003, 82, 2404.

[18] N. Bowden, W. T. S. Huck, K. E. Paul, G. M. Whitesides, Appl. Phys. Lett. 1999, 75, 2557.

[19] Z. B. Chen, Y. Y. Kim, S. Krishnaswamy, J. Appl. Phys. 2012, 112, 124319.

[20] T. Okayasu, H. L. Zhang, D. G. Bucknall, G. A. D. Briggs, Adv. Funct. Mater. 2004, 14, 1081.

[21] M. Watanabe, K. Mizukami, Macromolecules 2012, 45, 7128.

[22] W. T. S. Huck, N. Bowden, P. Onck, T. Pardoen, J. W. Hutchinson, G. M. Whitesides, Langmuir 2000, 16, 3497.

[23] W. Ding, Y. Yang, Y. Zhao, S. Jiang, Y. Cao, C. Lu, Soft Matter 2013, 9, 3720 .

[24] C. F. Guo, V. Nayyar, Z. Zhang, Y. Chen, J. Miao, R. Huang, Q. Liu, Adv. Mater. 2012, 24, 3010.

[25] H. Vandeparre, J. Léopoldès, C. Poulard, S. Desprez, G. Derue, C. Gay, P. Damman, Phys. Rev. Lett. 2007, 99, 188302.
[26] H. Vandeparre, P. Damman, Phys. Rev. Lett. 2008, 101, 124301.

[27] Liquid Crystals Beyond Displays: Chemistry, Physics, and Applications, (Ed: Q. Li), John Wiley \& Sons, Hoboken, USA 2012.

[28] Nanoscience with Liquid Crystals: From Self-Organized Nanostructures to Applications, (Ed: Q. Li) Springer, Heidelberg, Germany 2014.

[29] A. Agrawal, P. Luchette, P. Palffy-Muhoray, S. L. Biswal, W. G. Chapman, R. Verduzco, Soft Matter 2012, 8, 7138.

[30] A. Agrawal, T. H. Yun, S. L. Pesek, W. G. Chapman, R. Verduzco, Soft Matter 2014, 10, 1411.

[31] F. Greco, V. Domenici, S. Romiti, T. Assaf, B. Zupančič, J. Milavec, B. Zalar, B. Mazzolai, V. Mattoli, Mol. Cryst. Liq. Cryst. 2013, 572, 40

[32] S. H. Kang, J.-H. Na, S. N. Moon, W. I. Lee, P. J. Yoo, S.-D. Lee, Langmuir 2012, 28, 3576.

[33] L. T. de Haan, V. Gimenez-Pinto, A. Konya, T.-S. Nguyen, J. M. N. Verjans, C. Sánchez-Somolinos, J. V. Selinger, R. L. B. Selinger, D. J. Broer, A. P. H. J. Schenning, Adv. Funct. Mater. 2014, 24, 1251.

[34] K. Efimenko, M. Rackaitis, E. Manias, A. Vaziri, L. Mahadevan, J. Genzer, Nat. Mater. 2005, 4, 293.

[35] V. Chigrinov, Crystals 2013, 3, 149.

[36] O. Yaroshchuk, Y. Reznikov, J. Mater. Chem. 2012, 22, 286. 